0040-4039(94)E0393-C

\title{
STUDIES ON MORPHOLINOSPHINGOLIPIDS: POTENT INHIBITORS OF GLUCOSYLCERAMIDE SYNTHASE
}

\author{
Kenneth G. Carson and Bruce Ganem* \\ Department of Chemistry, Baker Laboratory \\ Cornell University, Ithaca, NY 14853-1301 USA
}

Norman S. Radin, Akira Abe, and James A. Shayman

Nephrology Division, Department of Internal Medicine University of Michigan, Ann Arbor, MI 48109 USA

Abstract: Synthetic 1-morpholino-1-deoxyceramides were designed to inhibit glucosylceramide synthase. The most potent inhibitor 2a possesses the unnatural $R, R$-configuration of $D$-threo-sphingosine.

Eucaryotic glycosphingolipids (GSLs) affect membrane physical properties, cell-cell and cell-matrix interactions, adhesiveness, cellular immune responses, and differentiation. ${ }^{1}$ GSLs have also been implicated in cancer cell metabolism. ${ }^{2}$ For example, malignant cells display marked abnormalities in their relative proportions of glycolipids, ${ }^{3}$ and produce GSLs with novel linkage and sugar specificities. ${ }^{4}$ Tumor cells also synthesize and shed excessive levels of GSLs which suppress lymphocyte responses in the host's immune system.

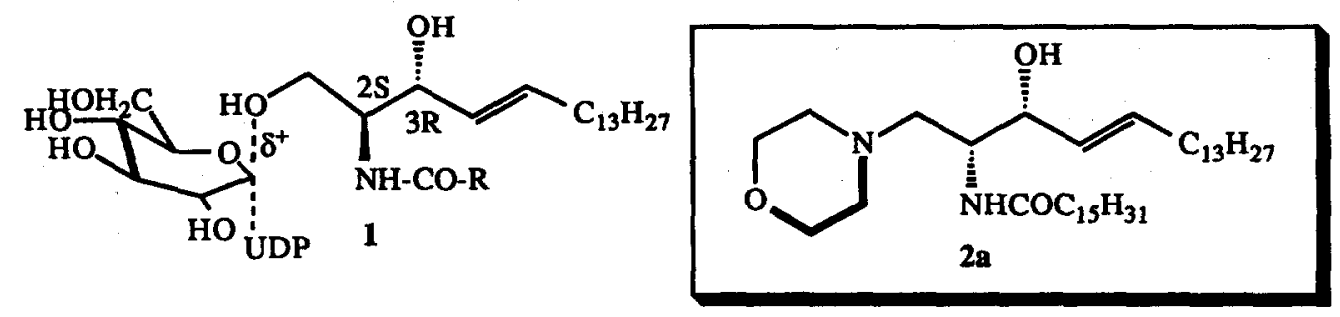

GSL biosynthesis begins with the coupling of UDP-glucose to $\mathrm{Cl}$ of an $\mathrm{N}$-acylsphingosine (ceramide).

The reaction is catalyzed by glucosyiceramide synthase (GleCer synthase; ceramide:UDP-glucose glucosyltransferase; EC 2.4.1.80), probably via a transition structure like 1.5 The enzyme plays a pivotal role in GSL biosynthesis and represents a promising cancer chemotherapy target, since inhibitors can retard or arrest tumor growth. 6 Here we report studies defining 1-morpholino-1-deoxyceramides such as $2 \mathrm{a}$ as potent GlcCer synthase inhibitors. 
Inhibitor design was based on the observation that D-threo-1-phenyl-2-decanoylamino-3-morpholino-1-

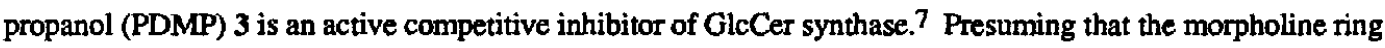
mimics the cationic charge of the GlcCer synthase transition state 1, the syn-stereochernistry in 3 suggests that the bioactive (1R,2R)-PDMP stereoisomer is at variance with the D-erythro-or anti-configuration of naturallyoccurring GSLs shown in (2S,3R)-1. This stereochemical difference was a central concern in our plan to design more potent, sphingosine-based GlcCer synthase inhibitors containing glucopyranose analogs having ring conformations related to $1 .^{8}$ To probe this stereochemical issue, we developed syntheses of all four isomeric 1-morpholino-1-deoxyceramides 2a-d, as shown in the Scheme.

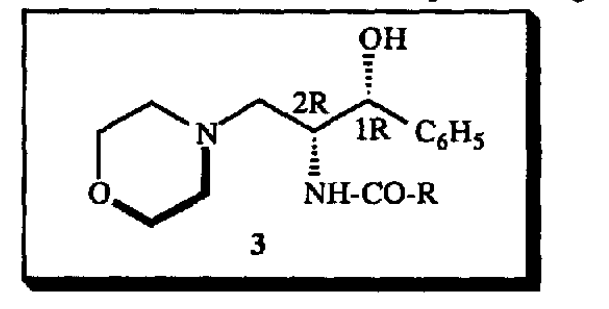

Our synthetic approach was based on the method of Evans et al. for the enantioselective aldol condensation of oxazolidinone 4 with unsaturated aldehyde 5.9 According to Abdel-Magid et al., ${ }^{10}$ the observed stereochemistry of condensation is influenced by chelation to the oxazolidinone oxygen in the transition state. In fact, condensation of 5 with the tin(II) enolate of 4 (prepared as shown in the Scheme) gave mostly $6 c$, whereas the $\mathrm{Zn}$ (II) enolate of 4 gave an inseparable mixture of $6 \mathrm{a}$ and $6 \mathrm{~b}$. Both reactions gave minor amounts of the (2S,3S) isomer $6 \mathbf{d}$, which could be separated by flash column chromatography.

The mixture of bromohydrins $6 \mathrm{a}$ and $6 \mathrm{~b}$ could not be resolved, but was separable after conversion to the corresponding azides $7 \mathrm{a}$ and $7 \mathrm{~b}$, following the procedure of Nicolaou et al. ${ }^{11}$ Alcohol $7 \mathrm{a}$ was then protected as its $t$-butyldimethylsilyl ether, and the chiral auxiliary was reductively removed to afford sphingol ether $8 a$. The primary alcohol in 89 was next activated as its triflate, and displacement with morpholine afforded aminoether 99. Reduction of the azide group in $9 \mathrm{a}$ was effected by transfer hydrogenation using ammonium formate as the hydrogen source. Subsequent $\mathrm{N}$-acylation and desilylation led to the final product $2 \mathrm{a}$ in good overall yield. ${ }^{12}$ This consitutes the first use of metal-dependent aldol condensations in sphingosine synthesis, and the first synthesis of 1-azaceramides. Diastereomers $2 \mathrm{~b}$-d were synthesized in like fashion from aldol adducts $6 \mathbf{b}-\mathbf{d}$.

Morpholinoceramides 2a-d were evaluated as inhibitors of GlcCer synthase from Madin-Darby canine kidney cell homogenates, using octanoyl sphingosine as glucose acceptor (thermostatted ultrasonic bath, triplicate assays). 13 Diastereomer 2 was clearly the most powerful inhibitor of GlcCer synthase (73\% inhibition at $5 \mu \mathrm{M}$ ),

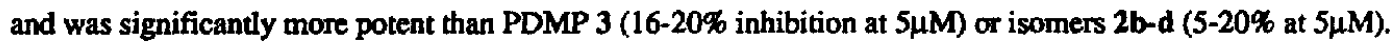




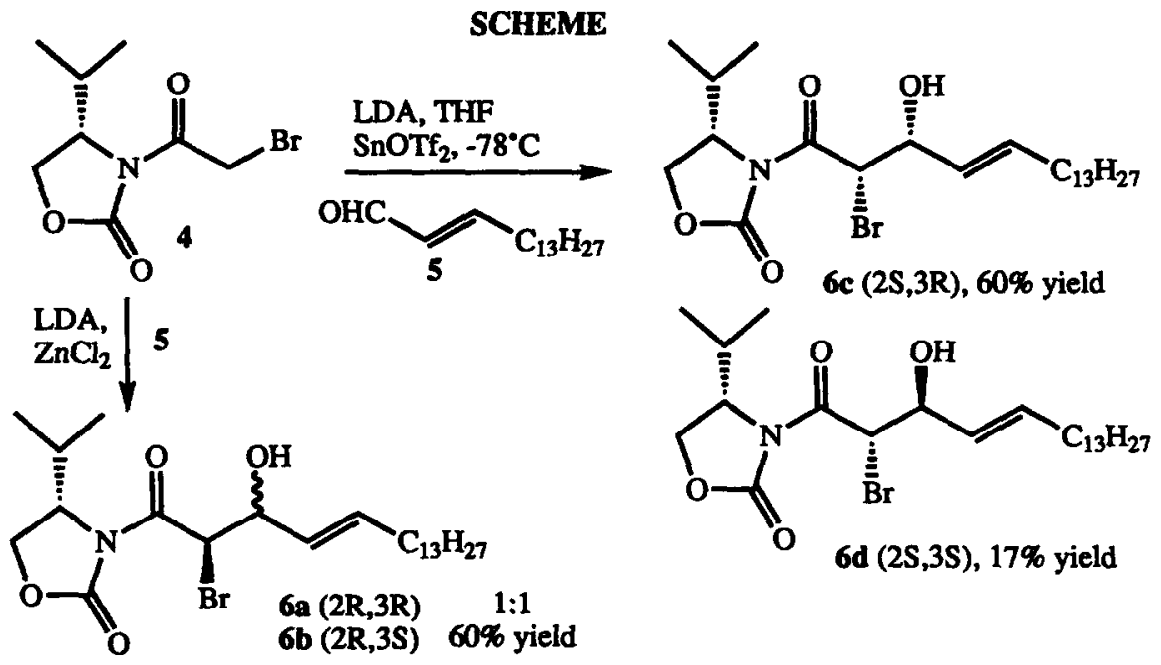

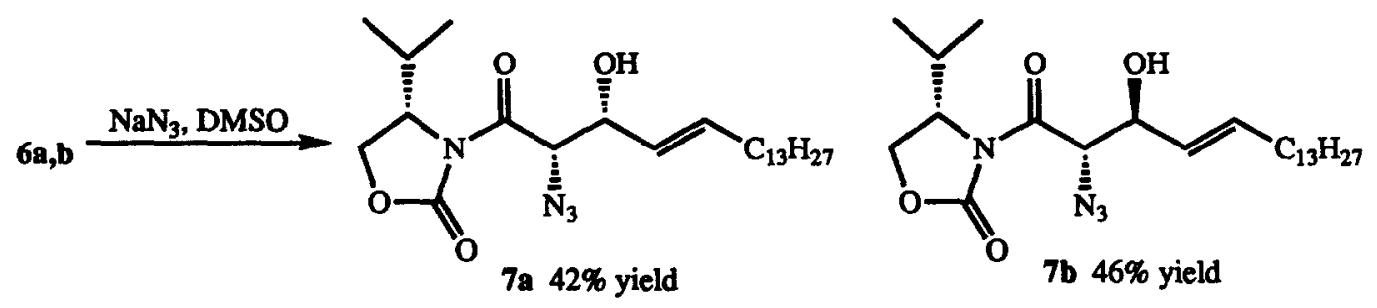

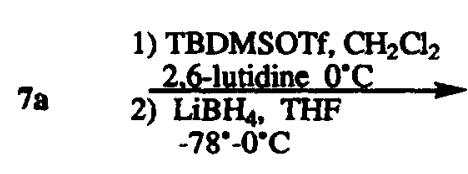

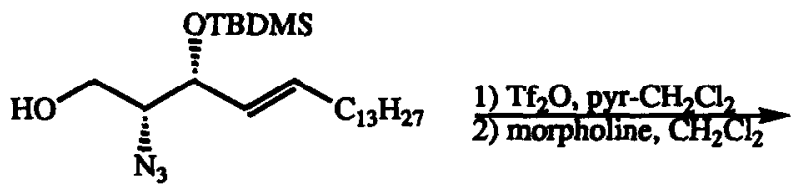

8a 46\% from 7a

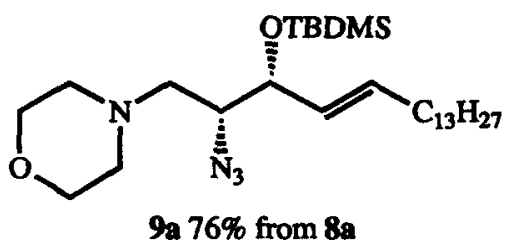
1) Lindlar's catalyst MeOH/EtOAc $\mathrm{HCO}_{2} \mathrm{NH}_{4}$ 2) $\mathrm{ClCOC}_{15} \mathrm{H}_{31}, \mathrm{Et}_{3} \mathrm{~N}$ DMAP, $\mathrm{CH}_{2} \mathrm{Cl}_{2}$ 3) TBAF, THF

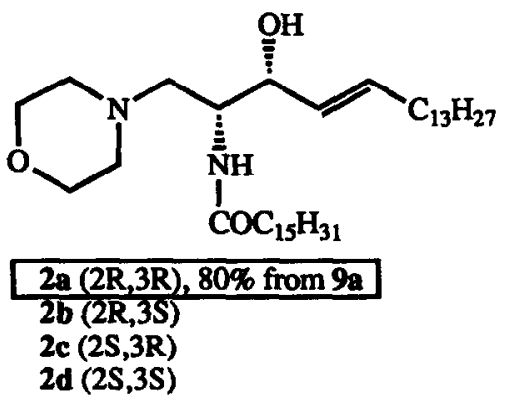


These findings set the stage for the refinement of GlcCer synthase transition structure mimics, including bi-substrate analogs and other active inhibitors based on the corresponding glucoamidrazone and glucoamidoxime derivatives 8 of sphingosine.

ACKNOWLEDGMENT: We thank the National Institutes of Health (GM 35712 to BG), the Glycolipid Research Fund, the University of Michigan Renal Center (Grant P50 DK39255), and the University of Michigan Comprehensive Cancer Center (Grant 2P30 CA 46592) for generous financial assistance. Support of the Cornell NMR Facility by the NSF and NIH is gratefully acknowledged.

\section{REFERENCES AND NOTES}

1. Hakomori, S. Annu. Rev. Biochem. 1981, 50, 733.

2. Radin, N. S.;Inokuchi, J. Biochem. Pharmacol. 1988, 37, 2879.

3. (a) Brady, R. O.; Fishman, P. H. Biochim. Biophys. Acta 1974, 355, 121; (b) Hildebrand, J.; Stryckmans, P. A.; Vanhouche, J. Biochim. Biophys. Acta 1972, 260, 272; Breimer, M. E. Cancer Res. 1980, 40, 897; (d) Hakomori, S. Biochim. Biophys. Acta 1975, 417, 55.

4. (a) Hanquing, M.; Avrova, N.; Mannson, J. E.; Molin, K.; Svennerholm, L. Biochim. Biophys. Acta 1986, 878, 360; (b) Fukuda, M. N.; Bothner, B.; Lloyd, K. O.; Rettig, W. J.; Tiller, P. R.; Dell, A. J. Biol. Chem. 1986, 261, 5145; (c) Nudelman, E.; Levery, S. B.; Kaizu, T.; Hakomori, S. J. Biol. Chem. 1986, 261, 11247.

5. Basu, S.; Kaufman, B.; Roseman, S. J. Biol. Chem. 1973, 248, 1388.

6. Inokuchi, J.; Mason, I.; Radin, N. S. Cancer Lett. 1987, 38, 23.

7. Inokuchi, J.; Radin, N. S. J. Lipid Res. 1987, 28, 565.

8. Papandreou, G.; Ganem, B. J. Am. Chem. Soc. 1991, 113, 8984.

9. Evans, D. A.; Nelson, J. V.; Voge, E.; Taber, T. R. J. Am. Chem. Soc. 1981, 103, 3099.

10. Abdel-Magid, A.; Pridgen, L. N.; Eggleston, D. S.; Lantos, I.; J. Am. Chem. Soc. 1986, 108, 4595.

11. Nicolaou, K. C.; Caulfield, T.; Kataoka, H.; Kumazawa, T. J. Am. Chem. Soc. 1988, 110, 7910.

12. Satisfactory ${ }^{1} \mathrm{H},{ }^{13} \mathrm{C}-\mathrm{NMR}, \mathrm{IR}$ and mass spectrometric data were obtained for all new compounds.

13. Shukla, G. S.; and Radin, N. S. Arch. Biochem. Biophys. 1990, 283, 372.

(Received in USA 17 December 1993; revised 2 February 1994; accepted 17 February 1994) 